\title{
A Summary of the Relationships Between Accident Indices and Rates Following a Redefinition of "Failure"
}

Dr. Alexander R. Craw

Technical Analysis Division

National Bureau of Standards

Washington, D. C. 20234

March 1973

Final Report

QC
100
. U56
$73-154$
1973

Prepared for

National Highway Traffic Safety Administration Department of Transportation

Washington, D. C. 20590 


\section{-}


NBSIR 73-154

\section{A SUMMARY OF THE RELATIONSHIPS \\ BETWEEN ACCIDENT INDICES AND \\ RATES FOLLOWING A REDEFINITION \\ OF "FAILURE"}

Dr. Alexander R. Craw

Technical Analysis Division

National Bureau of Standards

Washington, D. C. 20234

March 1973

Final Report

Prepared for

National Highway Traffic Safety Administration

Department of Transportation

Washington, D. C. 20590

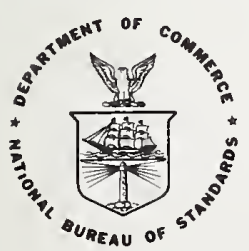

U. S. DEPARTMENT OF COMMERCE, Frederick B. Dent, Secretary

NATIONAL BUREAU OF STANDARDS, Richard W. noberts, Director 
Note: This report to the National Highway Traffic Safety Administration (NHTSA) has been prepared to serve as a mathematical appendix to a report to be published by the NHTSA. 
, 


\section{SUMMARY}

Using Cerrelli's association of "failure" with active involvements in the case of two vehicles accidents, one can define failure indices, accident involvement indices, failure rates, accident involvement rates for 1-vehicle, 2-vehicle and for the union class of 1 - and 2-vehicle accidents. This note presents in a condensed form all of the definitions of these measures, and a number of useful relationships and interrelationships that exist between these different measures. These formulae should prove useful in the calculation of the resulting indices and rates and of converting from one set of measures to another. 
$$
\text { , }
$$ 


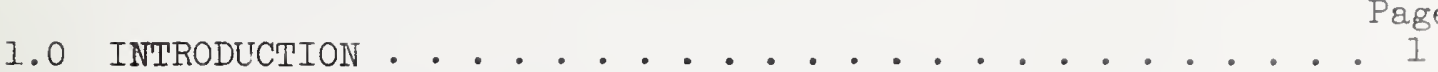

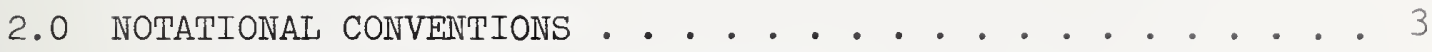

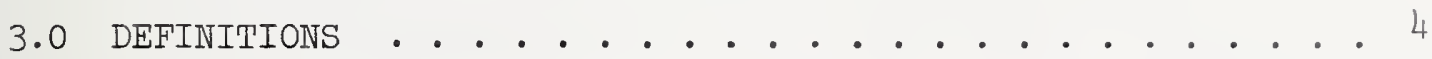

4.0 ACCIDENT INVOLVEMENT INDICES . . . . . . . . . . 5

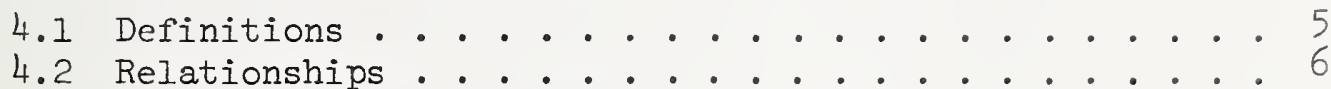

5.0 FAILURE INDICES ............... 6

$\begin{array}{lll}5.1 & \text { Definitions . . . . . . . . . . . . . . . . . . . . } 6 \\ 5.2 & \text { Relationships . } 6\end{array}$

6.0 FAILURE RATES .................... 6

6.1 Definitions ............... 6

6.2 Relationships.............. . . 7

7.0 ACCIDENT INVOLVEMENT RATES .............. 7

7.1 Definitions .............. . . 7

7.2 Relationships . . . . . . . . . . . . 7

8.0 INTERRELATIONSHIPS BETWEEN RATES ............ 8

9.0 INTERRELATIONSHIPS BETWEEN INDICES . . . . . . . . . 8

10.0 INTERRELATIONSHIPS BETWEEN RATES AND INDICES . . . . . 9

11.0 INTERRELATIONSHIPS BETWEEN FRACTIONAL

DEVIATIONS FROM NORM OF INDICES AND RATES ........9

12.0 DERIVATION OF INTERREIATIONSHIPS BETWEEN INDICES 
$$
\text { , }
$$ 
1.0 Introduction

In his recent paper: "Interpretation of the Accident Involvement Index,"l Ezio Cerrelli points out the pitfalls in interpretation (primarily by administrators) commonly associated with the currently used Accident Involvement Index (AII). A most common misinterpretation is that of considering it as an absolute measure of misperformance of a category of driver-vehicle combination, when in fact it is a relative measure. A second difficulty is that of interpreting each involvement as a "failure" in some sense and using involvements to measure the degree of "failure" for each category of driver-vehicle combination.

Cerrelli then proceeds with a rationale for associating one "failure" with each accident and then defines a Failure Index (FI) to be associated with each category of driver-vehicle. In the case of a one-vehicle accident, "failure" is identified with "involvement," but in the case of a two-vehicle accident, "failure" is associated only with an "active" involvement while passive involvement is considered as "non-failure." The basic relation is that "failure" implies involvement, but involvement does not necessarily imply "failure." This may be diagrammed for

l-vehicle accidents:

Failure Involvement 2-vehicle accidents: Failure Involvement

ITo be published as a National Highway Traffic Safety Administration (NHTSA) Report. 
As currently used the Accident Involvement Index is defined for the composite set (union) of the sets of 1- and 2-vehicle accidents. Originally Cerrelli defined separate failure indices for one-vehicle and two-vehicle accidents. It was pointed out by this author that failure and involvement indices could be obtained for each set of accident types (I-vehicle, 2-vehicle, composite), and that corresponding rates (ratios) could be defined as well. The latter turn out to be absolute rather than relative measures.

The purpose of this note is to present in a condensed form, for possible rapid reference and use, the definitions, relationships and interrelationships between traffic accident related indices and rates that result from Cerrelli's explicit identification of "failure" in the case of two vehicle accidents. These formulas should prove useful in the calculation of the indices and rates that result and of converting from one set to another. The notation used is that suggested to and employed by Cerrelli in his paper.

The reader should anticipate some general statements, such as: a. the ratio of fractional deviations from the norms for failure $\left\{\begin{array}{l}\text { indices } \\ \text { rates }\end{array}\right.$ is the ratio of total involvements to total failures time

the fractional deviations from the norms for involvement $\left\{\begin{array}{l}\text { indices, } \\ \text { rates }\end{array}\right.$

This holds true for each type of accident: 1-vehicle, 2-vehicle and the union of 1- and 2-vehicle accidents. 
b. For the union of 1 - and 2-vehicle accidents the

$$
\begin{aligned}
& \left\{\begin{array}{l}
\text { accident involvement } \\
\text { failures }
\end{array}\right\} \quad \text { index } \\
& \begin{array}{l}
\text { fractional deviations } \\
\text { from norm for }
\end{array}
\end{aligned}
$$

is equal to a weighted sum of the

$$
\begin{aligned}
& \begin{array}{ll}
\begin{array}{l}
\text { accident involvement } \\
\text { failure }
\end{array} & \text { indices } \\
\text { fractional deviations } \\
\text { from norm for }
\end{array} \\
&
\end{aligned}
$$

for 1- and 2-vehicle accidents.

\subsection{Notational Conventions}

Script letters (e.g., (6) will denote categories (classes)

or sets.

Script letters with subscripts denote subsets: $f_{k}$.

Upper case letters, with or without subscripts, denote integers: $\mathbb{E}_{\mathrm{K}}$.

Lower case letters, with or without subscripts, denote proportions:

$$
e_{k}=E_{k} / E \text {. }
$$

An unscripted single upper case letter denotes a summation

over the range of the subscript:

$$
E=E_{1}+E_{2}+\ldots+E_{n}=\sum_{k=1}^{n} E_{k} .
$$

1 refers to the set of 1 -vehicle accidents;

2 refers to the set of 2 -vehicle accidents;

* (or $u$ ) refers to the union of the sets of 1 - and 2-vehicle accidents. 
When double subscripts are used, the first subscript refers to the number of vehicles in the class of accidents under consideration, while the second subscript ref'ers to a particular category.

AII denotes an Accident Involvement Index;

AIR denotes an Accident Involvement Rate;

FI denotes a Failure Rate.

\subsection{Definitions}

$\mathrm{F}_{\mathrm{k}}=$ the number of exposure units associated with category $\mathrm{k}$

$e_{k}=$ the proportion of total exposure units associated with category $b_{k}=E_{k} / E$

3.1 I-Vehicle Accidents

$\mathrm{S}_{\mathrm{k}}=$ the number of single vehicle accident involvements

$=$ the number of single vehicle accident failures associated with $b_{\mathrm{k}}$.

$s=s_{1}+s_{2}+\ldots+s_{n}=\sum_{k=1}^{n} s_{k}$

$\mathrm{s}_{\mathrm{k}}=\mathrm{s}_{\mathrm{k}} / \mathrm{s}$

3.2 2-Vehicle Accidents

$I_{k}=$ the number of involvements in two vehicle accidents associated with $\mathscr{p}_{\mathrm{k}}$.

$I=\sum_{k=1}^{n} I_{k}$

$i_{k}=I_{k} / I$

$\mathrm{P}=\mathrm{I} / 2=$ the total number of passive involvements.

$\mathrm{p}_{\mathrm{k}}=\mathrm{P}_{\mathrm{k}} / \mathrm{P}$ (assumption iil, Cerrelli $\rightarrow \mathrm{p}_{\mathrm{k}}=\mathrm{e}_{\mathrm{k}}$ for 2-vehicle accidents) 
$A_{k}=$ the number of active involvements in $f_{k}$

$$
\begin{aligned}
& =I_{k}-P_{k} \\
A & =I-P=I / 2
\end{aligned}
$$

$a_{k}=\frac{A_{k}}{A}=\frac{I_{k}-P_{k}}{I / 2}\left[=\frac{I_{k}-e_{k} P}{I / 2}=\frac{I_{k}-e_{k} I / 2}{I / 2} \quad\right.$ by iii

$a_{k}+p_{k}=2 i_{k}$

3.3 Union of 1 - and 2-Vehicle Accidents

$I_{* k}\left(\right.$ or $\left.I_{k}^{*}\right)=S_{k}+I_{k}=$ total involvements associated with $k^{*}$

$I_{*}\left(\right.$ or $\left.I^{*}\right)=S+I$

$I_{*_{k}}\left(\right.$ or $\left.i_{k}^{*}\right)=I_{*_{k}} / I_{*}$

$A_{* k}\left(\right.$ or $\left.A_{k}^{*}\right)=S_{k}+A_{k}=$ total failures associated with $f_{k}$

$A_{*}\left(\right.$ or $\left.A^{*}\right)=S+A$

$a_{*_{k}}\left(\right.$ or $\left.a_{k}^{*}\right)=A_{*_{k}} / A_{*}$

4.0 Accident Involvement Indices

4.1 Definitions
(AII) ${ }_{I k}=\frac{S_{k} / S}{e_{k}}=\frac{S_{k}}{e_{k} S}=\frac{S_{k}}{e_{k}}$
$(A I I)_{1}=\frac{S / S}{e}=1$
(AII) $2 k=\frac{I_{k} / I}{e_{k}}=\frac{I_{k}}{e_{k} I}=\frac{i_{k}}{e_{k}}$
$(A I I)_{2}=\frac{I / I}{e}=I$
$(\text { AII })_{*_{k}}=\frac{I_{*_{k}} / I_{*}}{e_{k}}=\frac{i_{*_{k}}}{e_{k}}$
$(\text { AII })_{*}=\frac{I_{*} / I_{*}}{e}=1$ 
4.2 Relationships

$$
\begin{aligned}
(A I I)_{I}+ & (A I I)_{2}=2(A I I)_{*} \\
(A I I)_{* k} & =\frac{S}{I_{*}}(A I I)_{1 k}+\frac{I}{I_{*}}(A I I)_{2 k} \\
& =\text { weighted average of }(A I I)_{I k} \text { and }(A I I)_{2 k}
\end{aligned}
$$

5.0 Failure Indices

5.1 Definitions

$$
\begin{array}{lll}
(F I)_{I \mathrm{k}}=\frac{S_{\mathrm{k}} / \mathrm{S}}{e_{\mathrm{k}}}=\frac{\mathrm{S}_{\mathrm{k}}}{e_{\mathrm{k}}} & ; & (F I)_{I}=\frac{\mathrm{S} / \mathrm{S}}{\mathrm{e}}=1 \\
(F I)_{2 \mathrm{k}}=\frac{A_{\mathrm{k}} / \mathrm{A}}{e_{\mathrm{k}}}=\frac{\mathrm{a}_{\mathrm{k}}}{e_{\mathrm{k}}} & ; & (F I)_{2}=\frac{A / A}{\mathrm{e}}=1 \\
(\mathrm{FI})_{*_{\mathrm{k}}}=\frac{A_{*_{\mathrm{k}}} / \mathrm{A}_{*}}{e_{\mathrm{k}}}=\frac{a_{*_{\mathrm{k}}}}{e_{\mathrm{k}}} & ; & (F I)_{*}=\frac{A_{*} / A_{*}}{\mathrm{e}}=1
\end{array}
$$

5.2 Relationships

$$
(F I)_{*_{k}}=\frac{S}{A}(F I)_{1 k}+\frac{A}{A_{*}}(F I)_{2 k} ;(F I)_{1}+(F I)_{2}=2(F I)_{*}
$$

6.0 Failure Rates

6.1 Definitions:

$$
\begin{array}{lll}
(\mathrm{FR})_{1 \mathrm{k}}=\mathrm{S}_{\mathrm{k}} / \mathrm{E}_{\mathrm{k}} & ; & (\mathrm{FR})_{1}=\mathrm{S} / \mathrm{E} \\
(\mathrm{FR})_{2 \mathrm{k}}=\mathrm{A}_{\mathrm{k}} / \mathrm{E}_{\mathrm{k}} & ; & (\mathrm{FR})_{2}=\mathrm{A} / \mathrm{E} \\
(\mathrm{FR})_{*_{\mathrm{k}}}=\mathrm{A}_{*_{\mathrm{k}}} / \mathrm{E}_{\mathrm{k}} & ; & (\mathrm{FR})_{*}=\mathrm{A}_{*} / \mathrm{E}
\end{array}
$$

6 
6.2 Relationships

$$
\begin{aligned}
l_{*_{k}}^{(F R)} & =(F R)_{1 k}+(F R)_{2 k} ; \quad(F R)_{*}=(F R)_{1}+(F R)_{2} \\
(F R)_{1} & =\sum_{k} e_{k}(F R)_{1 k}=\text { weighted average over }(F R)_{1 k} \\
(F R)_{2} & =\sum_{k} e_{k}(F R)_{2 k}=\text { weighted average over }(F R)_{2 k} \\
(F R)_{*} & =\sum_{k} e_{k}(F R)_{*_{k}}=\text { weighted average over }(F R)_{* k} \\
\text { or }\left[(F R)_{j}\right. & =\sum_{k} e_{k}(F R)_{j k}, j=1,2, *
\end{aligned}
$$

7.0 Accident Involvement Rates

7.1 Definitions

$$
\begin{array}{lll}
(\text { AIR })_{I k}=S_{k} / E_{k} & ; & (\text { AIR })_{I}=S / E \\
(\text { AIR })_{2 k}=I_{k} / E_{k} & ; & (\text { AIR })_{2}=I / E \\
(\text { AIR })_{k}=I_{*} / E_{k} & ; & (\text { AIR })_{*}=I_{*} / E
\end{array}
$$

7.2 Relationships

$$
\begin{aligned}
& (A I R)_{I}=\sum_{k} e_{k}(A I R)_{I k}=\text { weighted average of }(A I R)_{I k} \\
& (A I R)_{2}=\sum_{k} e_{k}(A I R)_{2 k}=\text { weighted average of }(A I R)_{2 k} \\
& (A I R)_{*}=\sum_{k} e_{k}(A I R)_{* k}=\text { weighted average of }(A I R)_{* k} \\
& \text { or }(A I R)_{j}=\sum_{k} e_{k}(\text { AIR })_{j k}, j=1,2, * \\
& (A I R)_{* k}=(A I R)_{1 k}+(A I R)_{2 k} ;(A I R)_{1}+(A I R)_{2}=(A I R)_{*}
\end{aligned}
$$

7 
8.0 Interrelationships between Rates

$$
\left.\begin{array}{ll}
\left(\text { AIR }_{1 \mathrm{k}}=(\mathrm{FR})_{1 \mathrm{k}}\right. & \frac{(\mathrm{FR})_{1}}{(\mathrm{AIR})_{1}}=\frac{\mathrm{S}}{\mathrm{S}} \\
(\mathrm{AIR})_{2 \mathrm{k}}=(\mathrm{FR})_{2 \mathrm{k}}+\mathrm{P}_{\mathrm{k}} / \mathrm{E}_{\mathrm{k}} & \frac{(\mathrm{FR})_{2}}{(\mathrm{AIR})_{2}}=\frac{\mathrm{A}}{\mathrm{I}} \\
(\mathrm{AIR})_{*_{\mathrm{k}}}=(\mathrm{FR})_{*_{\mathrm{k}}}+\mathrm{P}_{\mathrm{k}} / \mathrm{E}_{\mathrm{k}} & \frac{(\mathrm{FR})_{*}}{(\mathrm{AIR})_{*}}=\frac{A_{*}}{I_{*}}
\end{array}\right\}
$$

If we define passive rates: $(P R)_{1 k} \equiv 0$

$$
\begin{aligned}
& (P R)_{2 k}=P_{k} / E_{k} \\
& (P R)_{*_{k}}=P_{k} / E_{k}
\end{aligned}
$$

then $(A I R)_{j k}=(F R)_{j k}+(P R)_{j k}, j=1,2, *$ For $j=1,2, *$ (FR) $\frac{j}{(\text { AIR })_{j}}$ equals the ratio of total failures to total involvements

9.0 Interrelationships between Indices
$(A I I)_{1 k}=(F I)_{1 k}$
$(F I)_{1 \mathrm{k}}=(\dot{A} I I)_{1 \mathrm{k}}$
$(\text { AII })_{2 k}=\frac{1}{2}\left[I+(F I)_{2 k}\right]$
$(F I)_{2 k}=2(A I I)_{2 k}-I$
$(\mathrm{AII})_{*_{\mathrm{K}}}=\frac{\mathrm{A}_{*}}{\mathrm{I}_{*}}(\mathrm{EI})_{*_{\mathrm{K}}}+\frac{\mathrm{A}}{\mathrm{I}_{*}}$
$(\mathrm{FI})_{*_{\mathrm{K}}}=\frac{I_{*}}{\mathrm{~A}_{*}}(\mathrm{AII})_{*_{\mathrm{K}}}-\frac{\mathrm{A}}{\mathrm{A}_{*}}$ 
10.0 Interrelationships between Rates and Indices

$$
\begin{array}{ll}
(F I)_{1 k}=\frac{(F R)_{1 k}}{(F R)_{1}}=(A I I)_{1 k} & (A I I)_{1 k}=\frac{(A I R)_{1 k}}{(A I R)_{1}} \\
(F I)_{2 k}=\frac{(F R)_{2 k}}{(F R)_{2}} & (A I I)_{2 k}=\frac{(A I R)_{2 k}}{(A I R)_{2}} \\
(F I)_{* k}=\frac{(F R)_{j k}}{(F R)_{*}} & (A I I)_{* k}=\frac{(A I R)_{*_{k}}}{(A I R)_{*}} \\
(F I)_{j k}=\frac{(F R)_{j k}}{(F R)_{j}}, j=1,2, * & (A I I)_{j k}=\frac{(A I R)_{j k}}{(A I R)_{j}}=j=1,2, *
\end{array}
$$

11.0 Interrelationships between Fractional Deviations from Norm of Indices and Rates

Since $(F I)_{j}=(A I I)_{j}=1$ for $j=1,2$, *

$$
\text { and } \begin{aligned}
(F I)_{j k} & =\frac{(F R)_{j k}}{(F R)_{j}} \text { and }(A I I)_{j k}=\frac{(A I R)_{j k}}{(A I R)_{j}} \text { for } j=1,2, *, \\
(F I)_{j k}-1 & =\frac{(F I)_{j k}-1}{1}=\frac{(F I)_{j k}-(F I)_{j}}{(F I)_{j}} \\
& =\frac{(F R)_{j k}}{(F R)_{j}}-1=\frac{(F R)_{j k}-(F R)_{j}}{(F R)_{j}}
\end{aligned}
$$

so $(F I)_{j k}-1=\frac{(F I)_{j k}-(F I)_{j}}{(F I)_{j}}=\frac{(F R)_{j k}-(F R)_{j}}{(F R)_{j}}, j=1,2, *$

and in the same way

$$
(A I I)_{j k}-1=\frac{(A I I)_{j k}-(A I I)_{j}}{(A I I)_{j}}=\frac{(A I R)_{j k}-(A I R)_{j}}{(A I R)_{j}}, j=1,2, *
$$




$$
\begin{aligned}
& \text { For } j=I \text {, } \\
& \frac{(F I)_{I k}-(F I)_{I}}{(F I)_{I}}=\frac{(F R)_{I k}-(F R)_{I}}{(F R)_{I}}=\frac{(A I I)_{I k}-(A I I)_{I}}{(A I R)_{I k}}=\frac{(A I R)_{I k}-(A I R)_{I}}{(A I R)_{1}}
\end{aligned}
$$

i.e., all fractional deviations are the same.

For $j=2$,

$\frac{(F I)_{2 k}-(F I)_{2}}{(F I)_{2}}=\frac{(F R)_{2 k}-(F R)_{2}}{(F R)_{2}}=\frac{2(A I I)_{2 k}-(A I I)_{2}}{(A I I)_{2}}=\frac{2(A I R)_{2 k}-(A I R)_{2}}{(A I R)_{2}}$

i.e., fractional deviations for failures are twice the fractional deviations for involvements.

$$
\text { For } j=*,(F I)_{*_{k}}-I=\frac{I_{*}}{A_{*}}\left[(A I I)_{*_{k}}-1\right]
$$

i.e., fractional deviations for failures is $I_{*} / A_{*}$ times the fractional deviations for involvements. Note: $I_{*} / A_{*}>I$.

Note that $I_{*} / A_{*}$ is the ratio of total involvements to total failures (active involvements).

$$
\text { For } \begin{aligned}
j & =1, \text { this ratio is } 1 \\
j & =2, \text { this ratio is } 2 \\
j & =* \text {, this ratio is } I_{*} / A_{*},
\end{aligned}
$$


so we can generalize:

The ratio of fractional deviations from the norms for failure is the ratio of total involvements to total failures times the fractional deviations from the norm of involvements. This holds for $j=1,2$, *.

For $j=*$,

$$
(F I)_{* k}-I=\frac{S}{A_{*}}\left[(F I)_{1 k}-I\right]+\frac{A}{A_{*}}\left[(F I)_{2 k}-1\right], A_{*}=S+A
$$

i.e., the fractional deviation of $\left\{\begin{array}{r}\text { failures } \\ \text { invivement }\end{array}\right\}$ from the norm for the union of the classes of 1 - and 2-vehicle accidents is equal to the weighted sum of the fractional deviations of $\left\{\begin{array}{l}\text { failures } \\ \text { involvements }\end{array}\right\}$ from the norm for 1- and 2-vehicle accidents.

$$
(A I I)_{* k}-I=\frac{S}{I_{*}}\left[(A I I)_{1 k}-1\right]+\frac{I}{I_{*}}\left[(A I I)_{2 k}-1\right], I_{*}=S+I
$$

One can combine the above results with those from sections 4.2 and 5.2 to state more generally:

For the union of 1 - and 2-vehicle accidents the $\begin{cases}\left\{\begin{array}{l}\text { accident involvement } \\ \text { failure }\end{array}\right. & \text { index } \\ \left\{\begin{array}{l}\text { fractional deviations } \\ \text { from norm for }\end{array}\right\} & \begin{array}{l}\text { indices } \\ \text { rates }\end{array} \\ \left.\left\{\begin{array}{l}\text { faccident involvement } \\ \text { failures } \\ \text { fractional deviations } \\ \text { from norm for }\end{array}\right\} \begin{array}{l}\text { indices } \\ \text { rates }\end{array}\right]\end{cases}$ is equal to a weighted sum of the for 1- and 2-vehicle accidents. 
Starting frorn

$$
\begin{aligned}
&(A I I)_{*_{k}}=\frac{S}{S+I}(A I I)_{1 k}+\frac{I}{S+I}(A I I)_{2 k}, I=2 A \\
&=\frac{S+A}{S+I}\left[\frac{S}{S+A}(A I I)_{1 k}+\frac{2 A}{S+A}(A I I)_{2 k}\right] \\
&=\frac{S+A}{S+I}\left[\frac{S}{S+A}(F I)_{1 k}+\frac{2 A}{S+A} \frac{I}{2}\left(I+(F I)_{2 k}\right)\right] \\
&=\frac{S+A}{S+I}[\underbrace{\left.\frac{S}{S+A}(F I)_{1 k}+\frac{A}{S+A}(F I)_{2 k}+\frac{A}{S+A}\right]}_{(F I)_{* k}} \\
&=\frac{S+A}{S+I}(F I)_{* k}+\frac{A}{S+I}=\frac{A_{*}}{I_{*}}(F I)_{* k}+\frac{A}{I_{*}, A_{*}}=S+A \\
& I_{*}=S+I
\end{aligned}
$$

or

$$
\begin{aligned}
(\mathrm{AII})_{*_{\mathrm{K}}} & =\frac{A_{*}}{I_{*}}(F I)_{*_{\mathrm{K}}}+\frac{A}{I_{*}} \\
& =\frac{A_{*}}{I_{*}}(F I)_{*_{\mathrm{k}}}-\frac{A_{*}}{I_{*}}+\frac{A_{*}}{I_{*}}+\frac{A}{I_{*}} \\
& =\frac{A_{*}}{I_{*}}\left[(F I)_{*_{\mathrm{k}}}-I\right]+\frac{A_{*}+A}{I_{*}}
\end{aligned}
$$

and

$$
(A I I)_{*_{k}}-I=\frac{A_{*}}{I_{*}}\left[(F I)_{*_{k}}-1\right]+\frac{A_{*}+A-I_{*}}{I_{*}}
$$

Since $A_{*}+A-I_{*}=S+2 A-S-I=2 A-I=0$, the last term falls out, and

$$
(A I I)_{*_{k}}-I=\frac{A_{*}}{I_{*}}\left[(F I)_{*_{k}}-I\right]
$$


BIBLIOGRAPHIC DATA SHEET

1. PUBLICATION OR REPORT NO. NBSIR-73-154
2. Gov't Accession No.

4. TITLE AND SUBTITLE

A Summary of the Relationships Between Accident Indices

and Rates Following a Redefinition of "Failure"

6. Performing Organization Code

8. Derforming Organization

Alexander R. Craw

7. AUTHOR(S)

Alexander R. Craw

9. PERFORMING ORGANIZATION NAME AND ADDRESS

NATIONAL BUREAU OF STANDARDS

DEPARTMENT OF COMMERCE

WASHINGTON, D.C. 20234

\section{NBSIR 73-154}

10. Project/Task/Work Unit No.

4314496

il. Contract/Grant No.

13. Type of Report \& Period Covered

Finel

14. Sponsoring Agency Code

15. SUP PLEMENTARY NOTES

16. ABSTRACT (A 200-word or less factual summary of most significant information. If document includes a signific ant bibliography or literature survey, mention it here.)

Using Cerrelli's association of 'failure' with active involvements in the case of two vehicles accidents, one can define failure indices, accident involvement indices, failure rates, accident involvement rates for 1-vehicle, 2 -vehicle and for the union class of 1 - and 2 -vehicle accidents. This note presents in a condensed form all of the definitions of these measures, and $a$ number of useful relationships and interrelationships that exist between these different measures. These formulae should prove useful in the calculation of the resulting indices and rates and of converting from one set of measures to another.

17. KEY WORDS (Alphabetical order, separated by semicolons)

accident indices; accident rates; failure indices; failure rates; highway accidents

18. AVAILABILITY STATEMENT

[5] UNLIMTTED.

FOR OF FICIAL DISTRIBUTION. DO NOT RELEASE TO NTIS.

\begin{tabular}{|l|l|}
\hline $\begin{array}{l}\text { 19. SECURITY CLASS } \\
\text { (THIS REPORT) } \\
\text { UNCL ASSIF IED }\end{array}$ & 21. NO. OF PAGES \\
\hline $\begin{array}{c}\text { 20. SECURITY CLASS } \\
\text { (THIS PAGE) } \\
\text {. } \\
\text { UNCL ASSIFIED }\end{array}$ & 22. Price \\
\hline
\end{tabular}




$$
\text { . }
$$



